\title{
Is there a doctor in the house?
}

\section{The presence of physicians in the direct-to-consumer genetic testing context}

\author{
Heidi Carmen Howard • Pascal Borry
}

Received: 29 April 2011 / Accepted: 5 August 2011 /Published online: 6 September 2011

(C) Springer-Verlag 2011

\begin{abstract}
Over the last couple of years, many commercial companies, the majority of which are based in the USA, have been advertising and offering direct-to-consumer (DTC) genetic testing services outside of the established health care system, and often without any involvement from a health care professional. In the last year, however, a number of DTC genetic testing companies have changed their provision model such that consumers must now contact a health care professional before being able to order the genetic testing service. In discussing the advent of this new model of service provision, this article also reviews the ethical and social issues surrounding DTC genetic testing and addresses the potential motivations for change, some barriers to achieving truly appropriate medical supervision and the present reality of DTC genetic testing for some psychiatric and neurological disorders.
\end{abstract}

Special Issue: Genetics and Democracy

H. C. Howard $(\bowtie) \cdot$ P. Borry

Centre for Biomedical Ethics and Law,

Katholieke Universiteit Leuven,

Kapucijnenvoer 35, Box 7001, 3000, Leuven, Belgium

e-mail: heidi.howard@med.kuleuven.be

H. C. Howard

Institute of Bio- and Medical Ethics Basel, University of Basel,

Missionstrasse 24,

CH-4056, Basel, Switzerland

P. Borry

Department of Medical Humanities, EMGO Institute for Health and Care Research, VU University Medical Center,

Amsterdam, The Netherlands

P. Borry

Department of Clinical Genetics, EMGO Institute for Health and Care Research, VU University Medical Center,

Amsterdam, The Netherlands
Since the advent of these commercial activities, critics have pointed a finger at the lack of medical supervision surrounding these services. The discussion herein, however, reveals how difficult it may be, despite the addition of a physician, to actually achieve adequate medical supervision within the present context of DTC genetic testing.

Keywords Direct-to-consumer - Genetic testing · Ethical

\section{Introduction}

According to a list compiled by the Genetics and Public Policy Centre (USA), there were at least 29 companies, most of which have headquarters in the USA, selling directto-consumer (DTC) genetic tests in May 2010 (Genetics and Public Policy Center 2011). The types of tests sold by these companies include single gene tests, multiple genes tests and genome-wide-testing also known as personal genome scanning, whereby hundreds of thousands to millions of genetic markers (often single nucleotide polymorphisms) are tested throughout the genome. Although the majority of the popular media coverage and much of the academic debates have focussed on companies selling genome-wide-testing services (i.e. from companies such as $23 \mathrm{andMe}$, deCODE and Navigenics), most DTC genetic testing companies, in fact, do not sell this type of testing. Also contributing to the variation in the DTC genetic testing market is the great deal of variation regarding the purpose of the tests on offer; for example, different tests can provide information regarding ancestry, carrier status, disease risk (presymptomatic, prenatal, susceptibility), nutrigenomics or pharmacogenomics.

DTC genetic testing has been defined as testing that "encompasses two separate but related issues: claims made about the tests to induce purchase (e.g. through advertising); 
and the sale of genetic testing services and provision of test results directly to consumers" (Genetics and Public Policy Center 2006). Others have referred to the term to refer to two distinct scenarios: (1) where there is "advertising of such tests directly to the public, with the actual ordering of the investigation and receipt of results involving a health care provider"; or (2) "where, in addition to advertising to the public, the request for testing is initiated by the patient and results are, in turn, provided directly to the patient, independently of the person's usual medical practitioner" (Mitchell et al. 2010). Similarly, the Human Genetics Commission (UK) extended the scope of their "Common Framework of Principles" on DTC genetic testing to situations where "tests are commissioned by the consumer but where a medical practitioner or health professional is involved in the provision of the service" (Human Genetics Commission 2010).

Regardless of which exact definition is preferred, the reality is that over the last couple of years, many commercial companies, the majority of which are based in the USA, have been advertising and offering DTC genetic testing services outside of the established health care system, and often without any involvement from a health care professional. Although in some cases, a health care professional may have been hired by the company to "formally" sign off on orders to circumvent legal issues (Mitchell et al. 2010; Wadman 2008), most companies did not require consumers to ever interact directly with a health care professional in order to obtain a genetic test. Hence, the main model of offer of DTC genetic testing, as it stood in the last few years, has involved no direct relationship between the consumer and a health care professional. That is to say that consumers would order genetic testing via the Internet or by phone without ever seeing or speaking to a health care professional. Specifically, the steps involved first ordering a test via the Internet or telephone, followed by the company sending a saliva swab kit to the consumer's home where he/she would follow the instructions in the kit and send a sample of saliva to the company. The company would then have DNA extracted from the saliva and analyse the DNA. The genetic test results would ultimately be returned to the consumer via the Internet (via email or a secured site). As a rule, the majority of DTC genetic testing companies would operate in this way without having the consumer ever consult with a health care professional. In the last year, however, a number of companies have changed their business model (to what we call herein the "new model") such that consumers now need to contact a medical doctor before being able to order the test from the company (e.g. Navigenics, Pathway Genomics, Counsyl). The aim of this article is to discuss the advent of this new model of DTC genetic testing provision. In doing so, we will first review the ethical and social issues with regard to DTC genetic testing in general, then discuss this new model of DTC genetic testing provision, including possible motivations for this change and potential barriers to achieving adequate medical supervision. We end with a brief discussion regarding genetic tests that are presently being offered directly to consumers for psychiatric and neurological conditions.

\section{DTC genetic testing: ethical and social issues}

Proponents of DTC genetic testing claim that the benefits of such a service include, among others, increased access for consumers, increased genetics and genomics education, added support for consumer autonomy and individual empowerment (Berg and Fryer-Edwards 2008). One of the main aspects outlined in the vision of these companies is that individuals can have a more active role in the creation, storage and protection of their personal genetic information and therefore have a better guarantee of the protection of their privacy (Foster and Sharp 2008). With respect to health-related genetic tests, some companies also suggest that knowing their disease risk (based on genetic and genomic information) will encourage individuals to modify their behaviour in order to achieve better health (Howard and Borry 2009). As a consequence, companies advance that this provides "the foundation for truly personalized medicine in which individuals are empowered not only with self-knowledge of their genetic risk, but also with the ability to take informed actions to prevent disease and preserve health" (Ledley 2002). In fact, the notions of consumer empowerment and democratization have been used recurrently to point out the potential benefits of offering genetic testing directly to the public. In general, the term democratization appears to have been used to mean "accessible to everyone" as opposed to the more specific notion of democracy where "people subject to a normative regime have some say, direct or indirect, in the creation or revision of that regime" (MacDonald and Walton 2009). Although not necessarily accessible to all socioeconomic classes (since DTC genetic testing usually costs hundreds of dollars), this notion of increased accessibility and democratization with respect to DTC genetic testing services may have been popularized by a press release from 23andMe in September 2008. The news release focussed on the reduced price of USD $\$ 399$ (down from USD $\$ 1,000$ ) for the genome-wide-testing service, and the first sentence of the press release stated that 23 andMe "today announced a substantial reduction in price for its Personal Genome ServiceTM, democratizing personal genetics and expanding the opportunity for more people to benefit from the genetic revolution" (23andMe 2011a). This concept was further supported by quotes from 23andMe co-founder Anne Wojcicki:

"We are excited that we are opening doors for more people to learn about their health and ancestry and for 
more people to be able to participate in advancing research. It is important to democratize personal genetics and make it more accessible." (23andMe 2011a)

This notion of increased accessibility as democracy was also expressed by Lee and Crawley (2009) who stated that the phenomenon of DTC genetic testing companies introducing a social networking component to their services is not only

"fostering a consumer empowerment movement, it promotes the trend of democratizing informationopenly sharing of data with all interested parties, not just the biomedical researcher-for the purposes of pooling data (increasing statistical power) and escalating the innovation process." (Lee and Crawley 2009)

At the other end of the spectrum, concerns raised by DTC genetic testing have centred on the scientific accuracy, clinical validity and utility of the DTC genetic tests (Janssens et al. 2008; Mihaescu et al. 2009; Foster et al. 2009; Field et al. 2010). As expressed by the American Society of Human Genetics:

"For a test to be of good quality, the laboratory performing it must be able to obtain the correct answer reliably, meaning that it detects a particular genetic variant when it is present and does not detect the variant when it is absent. A test's accuracy is referred to as 'analytic validity.' Further, there must be adequate scientific evidence to support the correlation between the genetic variant and a particular health condition or risk - the so-called clinical validity." (Hudson et al. 2007)

In addition, the European Society of Human Genetics (ESHG) underlined that it is

"of particular concern that their predictive value must be sufficient to meet the standards for clinical use. Clinical utility of a genetic test should be an essential criterion for deciding to offer this test to a person or a group of persons. (...) In light of these criteria, the ESHG opposes the premature DTC commercialization of various genetic tests." (European Society of Human Genetics 2010)

Concerns are also focussed on the absence and/or quality of the pre- and post-test genetic counselling (Wade and Wilfond 2006), as well as with the absence of individualised medical supervision (Hogarth et al. 2008). The lack of an adequate consent procedure, as well as the inappropriate genetic testing of minors, has also been criticized (Borry et al. 2009, 2010b). Further concerns include the research activities of DTC genetic testing companies (Borry et al. 2009; Howard et al. 2010), the (lack of) respect for privacy and the potential burden on public health resources (McGuire et al. 2009).

\section{The new model of DTC genetic testing: including a health care professional}

In contrast to the initial DTC genetic testing model of service provision, where consumers could obtain a test without ever interacting with a health care professional, what we call the "new model" of provision involves a health care professional. In the last year, a number of DTC genetic testing companies, such as Pathway Genomics, Navigenics, Counsyl and DNA Direct, have changed their provision model such that consumers must now contact a health care professional in order to obtain a genetic test. Although the exact procedural details vary somewhat between companies, the main idea is the same with respect to the need for consumers to communicate with a medical professional in order to obtain a test and in some cases, to discuss the results. DNA Direct, for example, has stated on their webpage addressed to consumers that

"We are no longer offering testing services directly to consumers; instead we are focusing our efforts on providing comprehensive yet easy-to-understand information and tools to consumers, physicians, hospitals, employers and health plans." (DNA Direct 2011)

In this case, the company requires consumers to "find a genomic Medicine Institute in your area" (DNA Direct 2011). The company website lists the contact information for five such centres across the USA. Similarly, Navigenics, which offers genome-wide-testing, now instructs consumers to "Sign up for Navigenics' services through your physician or corporate wellness program." They also help consumers find a physician that can order the test: "If you'd like to order through a physician, you can find a physician already participating in the Navigenics service, or help your doctor learn more about working with Navigenics by sharing the physician resources we provide" (Navigenics 2011b). The test results are returned via an online account that the customer can log onto. Although the company does not require a consultation with a health care professional for the return of results, they state that "Our Genetic Counselors are available to go through your report with you, answering any questions you may have. We can also work with you and your doctor to help you understand your genetic information as you develop personalized health strategies" (Navigenics 2011b). Pathway Genomics, another company that offers genome-wide-testing, also requires consumers to go through their physicians. Unlike Navigenics, however, Pathway Genomics provides the results to the physician: "When your results are ready, you will be contacted by your physician. They will provide you with an easy-to-understand, comprehensive report of your DNA analysis" (Pathway Genomics 2011). 


\section{Why involve health care professionals?}

This new model begs the question: why would companies want to change their model of provision? This question is especially pertinent since DTC genetic testing companies have emphasized the notions of autonomy, empowerment and convenience, in regard to DTC genetic testing (Borry et al. 2010a). In a way, adding a "gatekeeper" or offering tests through doctors contradicts some of the strongest claims continuously made by these companies.

Firstly, perhaps companies wanted to answer some of the critics with regard to the lack of physician involvement (Anderson 2009). In particular, various professional guidelines, including those from the American Medical Association (2008) and the American Congress of Obstetricians and Gynaecologists (2008), have emphasized the need for individualised care from a qualified medical professional. Furthermore, in addition to its statement on the subject in 2008, the American Medical Association (2008) recently (February 2011) sent a letter to the an expert panel of the Food and Drug Association (FDA) in the USA recommending that "genetic testing, except under the most limited circumstances, should be carried out under the personal supervision of a qualified health care professional" (American Medical Association 2011).

Furthermore, the European Society of Human Genetics stated that

"the offer of genetic tests providing health-related information, in the absence of clinical indications and individualised medical supervision, may compromise patient health. Key concerns are the provision of sufficient information about the purpose and appropriateness of testing, its possibilities and limitations, as well as the clinical significance of testing." (European Society of Human Genetics 2010)

This idea is endorsed by various regulatory organisations. In Europe, the Committee of Ministers of the Council of Europe approved on May 7, 2008 an additional protocol concerning genetic testing for health purposes to the Convention on Human Rights and Biomedicine (Council of Europe 2008a). In article 7.1, this document states that "a genetic test for health purposes may only be performed under individualised medical supervision." As outlined in the explanatory report, this article has been

"driven by the concern to enable the person concerned to have suitable preliminary information with a view to an informed decision regarding the carrying out of this test and, if appropriate, to have access to an appropriate genetic counselling. A precise evaluation of the situation of the person concerned, involving direct contact with him or her, is a determining element in that respect. A mere telephone conversation with a medical doctor, for example, does not allow for such evaluation." (Council of Europe 2008b)

Moreover, based on the need for individualised and faceto-face medical supervision, DTC genetic testing is prohibited in some European countries (i.e. Switzerland and France) (Borry 2008, 2010a).

Secondly, it is also possible that the intensified scrutiny from the FDA since Spring 2010 contributed, in some way, to this change in model. Following the partnership announcement between Pathway Genomics and the drugstore chain Walgreens, to sell DTC genetic tests, the FDA decided to investigate the activities of DTC companies more carefully (Allison 2010; Borry et al. 2010a). Between May and July 2010, the FDA sent letters to various companies telling them that they were unable to "identify any Food and Drug Administration clearance or approval number" (Food and Drug Administration 2010b). Moreover, in mid-July 2010, the FDA held a meeting to discuss the oversight of laboratory-developed tests, and the FDA advisory panel had a meeting in March 2011 to further discuss issues related to DTC genetic testing (Food and Drug Administration 2010a; Department of Health and Human Services 2011). Under such scrutiny, perhaps some companies understood the medical and ethical advantages of including a physician and/or felt that including a physician would make them appear more legitimate.

Thirdly, the motivation for change could have simply been an economic one in order to attract more customers via medical doctors. One cannot, all together, discard the notion that these companies had always planned, or at least considered, "pairing up" with clinicians to sell their tests. Companies could continue to focus their marketing efforts on consumers while also increasing advertising to physicians. In this way, even if regulations were put into place whereby genetic testing must be administered via a physician, by advertising to both groups, companies could potentially assure consumer demand as well as obtain physician collaboration and consequently "more" consumer confidence.

Will including a health care professional as a gatekeeper really help?

Lessons from direct-to-consumer advertising of prescription drugs

The promotion of genetic testing services by DTC genetic testing companies (especially those which are now following this new model of provision) may be compared to that of prescription drug companies in the USA (one of the few countries, along with New Zealand, where direct-to-consumer advertising (DTCA) of prescription drugs is legal). The claims 
made by proponents of DTCA of prescription drugs are very similar to those made by DTC genetic testing companies. For example, the former say that advertisements aimed at patients are a good way to: inform patients, increase their awareness of treatment options, increase health awareness, improve patientdoctor communication and ultimately result in better health outcomes (Humphreys 2009; Gilbody et al. 2005). Opponents of DTCA of prescription medicine have highlighted that advertisements provide biassed information, which mostly produce unrealistic expectations of the benefits of the advertised drugs. Further, it has been stated that physicians might be pressured to prescribe specific drugs even if they think these are not appropriate for both the individual patient and the health care system. (Mintzes 2002) Finally, based on a systematic review conducted by Gilbody and colleagues "direct to consumer advertising is associated with increased prescription of advertised products and there is substantial impact on patients' requests for specific drugs and physicians' confidence in prescribing" (Gilbody et al. 2005). Based on the similarities between DTCA of prescription drugs and DTC genetic testing services, it is likely that the consequences of the promotion of DTC genetic testing will be similar to those reported for DTCA of prescriptions drugs. Although gaining access to consumers via physicians may appear on the surface to "fix" the problem of lack of health care supervision or gatekeeping, the fact is that companies could still, in essence, be driving consumers toward their products by creating a needless demand. Consumers would then demand these genetic tests from their physicians who, based on studies of advertising of pharmaceuticals, are likely to deliver them (Lurie 2009). Although adding a physician to a DTC genetic testing service seems to solve some of the concerns that have been raised in the context of DTC genetic testing, it raises new questions that are related to (a) the capabilities of the physician to understand, interpret and communicate genetic and genomic testing results and (b) the extent of physician involvement (including his/her impartiality).

\section{A look at genetic education}

First of all, even if a non-geneticist physician is involved in the commercial provision of genetic testing (and disregarding, for a moment, the previously mentioned issues surrounding advertising), it does not mean that this physician is capable of being an appropriate gatekeeper. Various studies have shown that the majority of non-geneticist physicians are not equipped or prepared to adequately deal with genomic or genetic testing and lack adequate knowledge and training to provide qualitative genetic counselling (Harris et al. 2006; Burke and Emery 2002; Salari 2009). Therefore, it is certainly questionable whether these physicians are really properly equipped to offer appropriate medical supervision: to offer information about tests to patients; to assess the adequacy of a specific test and guide patients away from unneeded tests; and to interpret, contextualize and communicate the results to patients and to assure appropriate follow-up.

Admittedly, in order to properly perform all of these tasks for genetic and genomic testing, the physician in question must be suitably educated. On its website, Navigenics offers the contact information of 65 medical doctors from 17 states in the USA and one province (Ontario) in Canada, who have "completed training on integrating Navigenics' genetic testing services into their practice" (Navigenics 2011a). Based on the biographic information provided on the Navigenics website, these doctors are usually trained as family physicians or internists and not formally trained in clinical genetics. A situation where consumers are requesting genome-wide-testing from physicians who are not clinical geneticists, and who have received 'training' from the very company selling the test, may not represent the type of "gatekeeper" critics had in mind.

\section{Extent of physician involvement in care}

If the case of Navigenics is the norm for DTC genetic testing companies, and most of the physicians "linking" consumers to companies are not formally trained to deal with genetics information, concerns arise regarding the extent of such a physician's involvement in a patient's care. Can simply writing out a prescription for a genetic test be considered adequate medical supervision? Will these physicians go beyond writing the prescription and undertake a genuine care relationship with the consumer/ patient? Even if they are expected to do this, without the basic gatekeeping abilities mentioned above, it will be difficult for physicians to make decisions in the best interest of their patient. Even if some companies return results to the physician who in turn discusses them with the patient, again the issue of lack of proper education in genetics is a concern. Furthermore, as alluded to earlier, similar to the case for prescription drugs, the issue of bias and partiality is a concern with DTC genetic testing companies advertising to physicians and offering them "training". Such promotion strategies for prescription drugs have been shown to increase brand recognition and bias prescribing (Fischer et al. 2009). Furthermore, despite the clear potential for a conflict of interest, continuing medical education (CME) in the USA is often funded directly or indirectly by pharmaceutical or medical device companies (Rodwin 2010). An unfortunate consequence is that advertising is often confused with education (Rodwin 2010). The lack of genetics education for a non-geneticist coupled with the willingness of some DTC genetic companies to "train" physicians would suggest that a similar situation may be created for genetics as has been the case for prescription drugs. 


\section{DTC genetic testing for neurological and psychiatric conditions}

Although the problems related to a lack of true medical supervision for genetic testing exist for all genetic diseases, adverse implications are particularly relevant for common complex diseases (Mitchell et al. 2010). For example, is it acceptable or responsible to allow companies to sell tests for common complex disorders such as psychiatric and neurological conditions without proper medical supervision involving both pre- and post-test counselling as well as any necessary post-test follow-up? Will the addition of a physician who will only write a prescription help to achieve any of these tasks? Indeed, tests for schizophrenia, bipolar disorder, alcohol dependence and Alzheimer's disease are being offered directly to consumers. Half a dozen DTC genetic testing companies (DNA dimensions, Graceful Earth, My Genome, Matrix Genomics, Pathway Genomics, deCODE and Navigenics) offer a test for Alzheimer's disease, and most of them specify that they are testing for apolipoprotein E (APOE) variants. This offer is contradictory to the recommendation that presymptomatic testing for non-Mendelian Alzheimer's (i.e. the common complex form) not be offered due to the low sensitivity and specificity of the test (Mihaescu et al. 2010). Furthermore, at least three other DTC genetic testing companies sell the APOE genotype test to give information regarding cardiovascular disease. Will the non-geneticist physician know that in returning information about the latter disease she could also be giving some information about Alzheimer's disease and vice versa? Admittedly, information from the REVEAL study group does suggests that the disclosure of APOE genotype results to adult offspring of Alzheimer patients did not result in significant short-term psychological risk (Green et al. 2009). However, this testing was done within the context of a strictly structured and supervised research project with the required medical supervision as well as pre- and post-testing genetic counselling for research subjects (Green et al. 2009). This cannot be compared to the services of companies where no medical supervision is offered (or suggested) or even to Nagivenics, which appears to leave it to the consumer's discretion if he/she wants to receive the results via a physician and/or wants the help of a genetic counsellor (Navigenics 2011b).

Tests for schizophrenia, bipolar disorder, and alcohol dependence are also being offered directly to consumers via 23 andMe. They offer testing for these conditions and state that information for testing is based on "Preliminary Research Reports" which "are based on peer-reviewed, published research where the findings still need to be confirmed by the scientific community. They also include topics where there may be contradictory evidence" (23andMe 2011b). How will the consumer understand this?
How will the non-geneticist physician understand this? If genetic markers are not commonly being used for these psychiatric conditions in clinical practice, is it acceptable to be giving this information in the same manner as telling someone of his/her susceptibility to freckling or to cleft lip and palate? Additional companies which were featured in Science in 2008 regarding the commercial offer of genetic tests for mental illnesses (Couzin 2008) such as Psynomics (bipolar disease) and SureGene (genes involved in psychopathology and antipsychotic drug response in schizophrenia and bipolar disorder) still have functional websites (hence a form of advertisement) but are not selling genetic testing at the moment (Psynomics 2011; SureGene 2010). Above and beyond the scientific issues of technical and clinical validity, ethical and social issues revolving around the use of biomarkers in psychiatry abound, and include but are not limited to issues of identity, discrimination, stigma labelling, social identities and beliefs and (lack of) education (Singh and Rose 2009). Even if the scientific criteria for biomarkers for a psychiatric or neurological disease had been met, these social and ethical issues should be addressed before offering any form of routine genetic testing to patients (or consumers). Furthermore, given that these issues have to be addressed in a more personal form with each result, it is difficult to envisage how this can be done responsibly in either the old or new model of DTC genetic testing.

\section{Conclusion}

In conclusion, the new model of provision of DTC genetic testing, whereby a non-geneticist physician is now involved in the distribution of these testing services, may not properly address the concern of lack of medical supervision. First of all, a lack of education in genetics may make the non-geneticist physician an inadequate gatekeeper. To be fair, it is likely that some results from a genome-wide scan and full genome sequence would be a challenge to interpret even for clinical geneticists and genetic counsellors; however, this is no reason to accept improperly trained or educated physicians to supervise genetic testing. If genomic science is to infiltrate health care and public health as some predict it will, it is obvious there is an urgent need to improve and increase genetics and genomics education for physicians. We excluded any extensive discussion, herein, regarding the issue of genetic counsellors and their role in DTC genetic testing simply because in this new model, companies introduced physicians, and not genetic counsellors. This, by no means, diminishes the potentially important contribution genetic counsellors could make to the DTC genetic testing context in particular and to genomic medicine in general.

Furthermore, the issue of advertising directly to consumers could also be a barrier to adequate medical supervision. DTC 
and direct-to-physician advertising (including CME) may, indeed, increase demand and prescriptions of useless genetic tests. Furthermore, one should not exclude the possibility that the inclusion of a medical physician, who in fact may only be writing out prescriptions for genetic tests, may provide a false sense of reassurance to consumers that all these tests are medically useful and appropriate. The issue of inadequate medical supervision may also be a concern in the traditional health care system for a number of different medical specialties, but this is no reason for stakeholders in genetics and genomics to find it acceptable in this specialty.

Companies like 23andMe will argue that they are making access to genomic information more democratic (23andMe 2011a). Although we may debate over the meaning of democratic, there is no doubt that they are increasing public access to genetic and genomic testing. The question we are concerned with, however, is: are they increasing access to genetic and genomic testing in an ethical and responsible way? To help answer this question and conclude, we quote Singh and Rose who state that more

"social-science research is required to examine the extent to which such commercialization of biomedical information, and its availability on a direct-to-consumer basis, may encourage individuals and families- and perhaps medical and non-medical professionals- to develop unrealistic ideas about the explanatory power of this information." (Singh and Rose 2009)

Acknowledgements $\mathrm{HCH}$ is funded by the European Commission FP7 Marie Curie initiative, and PB is funded by the Research Fund Flanders (FWO).

Conflict of interest The authors have no conflicts of interests to disclose

\section{References}

23 and Me (2011a) 23 and Me democratizes personal genetics. https:// www.23andMe.com/about/press/20080909b/ Accessed 29 Apr 2011

23 and $\mathrm{Me}$ (2011b) Health reports: complete list. https:// www.23andMe.com/health/all/ Accessed 22 Feb 2011

Allison M (2010) Genetic testing clamp down. Nat Biotechnol 28:633

American College of Obstetricians and Gynaecologists (2008) ACOG Committee Opinion No. 409: Direct-to-consumer marketing of genetic testing. Obstet Gynecol 111:1493-1494

American Medical Association (2008) Direct-to-consumer advertising and provision of genetic testing. www.ama-assn.org/ama1/pub/ upload/mm/471/bot7.doc Accessed 23 Feb 2011

American Medical Association (2011) AMA letter to the FDA regarding molecular and clinical genetics panel of medical devices advisory committee. http://www.ama-assn.org/ama1/pub/ upload/mm/399/consumer-genetic-testing-letter.pdf Accessed 27 Apr 2011
Anderson EE (2009) Direct-to-consumer personal genome services: need for more oversight. Virtual Mentor 11:701

Berg C, Fryer-Edwards K (2008) The ethical challenges of direct-toconsumer genetic testing. J Bus Ethics 77:17-31

Borry P (2008) Europe to ban direct-to-consumer genetic tests? Nat Biotechnol 26:736-737

Borry P, Howard HC, Senecal K, Avard D (2009) Direct-to-consumer genome scanning services. Also for children? Nat Rev Genet 10:8

Borry P, Cornel MC, Howard HC (2010a) Where are you going, where have you been. Direct-to-consumer genetic tests for health purposes. J Comm Genet 1:101-106

Borry P, Howard HC, Senecal K, Avard D (2010b) Health-related directto-consumer genetic testing: a review of companies' policies with regard to genetic testing in minors. Fam Cancer 9:51-59

Burke W, Emery J (2002) Genetics education for primary-care providers. Nat Rev Genet 3:561-566

Council of Europe (2008a) Additional protocol to the convention on human rights and biomedicine, concerning genetic testing for health purposes. http://conventions.coe.int/Treaty/EN/Treaties/ Html/TestGen.htm Accessed 22 Feb 2011

Council of Europe (2008b) Explanatory report to the additional protocol to the convention on human rights and biomedicine, concerning genetic testing for health purposes. http://conventions.coe.int/Treaty/ EN/Reports/Html/TestGen.htm Accessed 22 Feb 2011

Couzin J (2008) Gene tests for psychiatric risk polarize researcher. Science Magazine 319:274-278

Department of Health and Human Services (2011) Summary from the molecular \& clinical genetics panel meeting-March 8 \& 9, 2011. U.S. Food and Drug Administration, Silver Spring. http://www. fda.gov/downloads/AdvisoryCommittees/CommitteesMeeting Materials/MedicalDevices/MedicalDevicesAdvisoryCommittee/ MolecularandClinicalGeneticsPanel/UCM246907.pdf, Accessed 22 Aug 2011

DNA Direct (2011) New resources for genetic testing. http://www. dnadirect.com/web/consumers, Accessed 17 Feb 2011

Food and Drug Administration (2010a) FDA/CDRH Public meeting: oversight of laboratory developed tests (LDTs), Date July 19-20, 2010. www.fda.gov/MedicalDevices/NewsEvents/Workshops Conferences/ucm212830.htm\#webcast. Accessed 22 Feb 2011

Food and Drug Administration (2010b) Letters to manufacturers concerning genetic tests. www.fda.gov/MedicalDevices/Product sandMedicalProcedures/InVitroDiagnostics/ucm219582.htm Accessed 22 Feb 2011

European Society of Human Genetics (2010) Statement of the ESHG on direct-to-consumer genetic testing for health-related purposes. Eur J Hum Genet 18:1271-1273

Field A, Krokosky A, Terry SF (2010) Direct-to-consumer marketing of genetic tests: access does not reflect clinical utility. GeneTest Mo Biom 14:731-732

Fischer MA, Keough ME, Baril JL, Saccoccio L, Mazor KM, Ladd E, Worley AV, Gurwitz JH (2009) Prescribers and pharmaceutical representatives: why are we still meeting? J Gen Intern Med 24:795-801

Foster MW, Sharp RR (2008) The contractual genome: how direct-toconsumer genomic services may help patients take ownership of their DNA. Persona Med 5:399-404

Foster MW, Mulvihill JJ, Sharp RR (2009) Evaluating the utility of personal genomic information. Genet Med 11:570-574

Genetics and Public Policy Center (2006) Direct-to-consumer genetic testing: empowering or endangering the public? http://www. dnapolicy.org/policy.issue.php?action=detail\&issuebrief_id=32. Accessed 17 Feb 2011

Genetics and Public Policy Center (2011) http://www.dnapolicy.org/ resources/AlphabetizedDTCGeneticTestingCompanies11.10.pdf. Accessed 17 Feb 2011 
Gilbody S, Wilson P, Watt I (2005) Benefits and harms of direct to consumer advertising: a systematic review. Qual Saf Health Care 14:246

Green RC, Roberts JS, Cupples LA, Relkin NR, Whitehouse PJ, Brown T, Eckert SLR, Butson M, Sadovnick AD, Quaid KA (2009) Disclosure of APOE genotype for risk of Alzheimer's disease. New Engl J Med 361:245

Harris R, Challen K, Benjamin C, Harris H (2006) Genetic education for non-geneticist health professionals. Public Health Genomics 9:224-226

Hogarth S, Javitt G, Melzer D (2008) The current landscape for directto-consumer genetic testing: legal, ethical, and policy issues. Annu Rev Genom Hum Genet 9:161-182

Howard HC, Borry P (2009) Personal genome testing: do you know what you are buying? Am J Bioeth 9:11-13

Howard HC, Knoppers BM, Borry P (2010) Blurring lines. The research activities of direct-to-consumer genetic testing companies raise questions about consumers as research subjects. EMBO Rep 11:579-582

Hudson K, Byers P, Burke W, Javitt G (2007) ASHG statement on direct-to-consumer genetic testing in the United States. Am J Hum Genet 81:635-637

Human Genetics Commission (2010) A common framework of principles for direct-to-consumer genetic testing services. http://www.hgc.gov. uk/Client/document.asp?DocId=280\&CAtegoryId=10. Accessed 17 Feb 2011

Humphreys G (2009) Direct-to-consumer advertising under fire. Bull World Health Organ 87:576-577

Janssens AC, Gwinn M, Bradley LA, Oostra BA, van Duijn CM, Khoury MJ (2008) A critical appraisal of the scientific basis of commercial genomic profiles used to assess health risks and personalize health interventions. Am J Hum Genet 82:593-599

Ledley F (2002) A consumer charter for genomic services. Nat Biotechnol 20:767

Lee SS, Crawley L (2009) Research 2.0: social networking and directto-consumer (DTC) genomics. Am J Bioeth 9:35-44

Lurie P (2009) DTC advertising harms patients and should be tightly regulated. J Law Med Ethics 37:444-450

MacDonald C, Walton N (2009) Personal genomics: democratization, or empowerment, or 'something'. Am J Bioeth 9:46-48
McGuire A, Diaz CM, Wang T, Hilsenbeck S (2009) Social networkers' attitudes toward direct-to-consumer personal genome testing. Am J Bioeth 9:3-10

Mihaescu R, Van HM, Sijbrands EJ, Uitterlinden AG, Witteman JC, Hofman A, van Duijn CM, Janssens AC (2009) Evaluation of risk prediction updates from commercial genome-wide scans. Genet Med 11:588-594

Mihaescu R, Detmar SB, Cornel MC, van der Flier WM, Heutink P, Hol EM, Rikkert MGMO, van Duijn CM, Janssens ACJW (2010) Translational research in genomics of Alzheimer's disease: a review of current practice and future perspectives. Journal of Alzheimer's Disease 20:967-980

Mintzes B (2002) For and against: direct to consumer advertising is medicalising normal human experience: for. $\mathrm{Br}$ Med $\mathrm{J}$ 324:908

Mitchell PB, Meiser B, Wilde A, Fullerton J, Donald J, Wilhelm K, Schofield PR (2010) Predictive and diagnostic genetic testing in psychiatry. Clin Lab Med 30:829-846

Navigenics (2011a) Find a physician. http://www.navigenics.com/ visitor/about_us/find_a_physician/. Accessed 17 Feb 2011

Navigenics (2011b) How our services work. http://www.navigenics. com/visitor/what_we_offer/how_it_works/. Accessed 17 Feb 2011

Pathway Genomics (2011) Pathway's genetic insights. https://www. pathway.com/dna-reports Accessed 17 Feb 2011

Psynomics (2011) Psynomics. http://www.psynomics.com/products. php. Accessed 22 Feb 2011

Rodwin MA (2010) Drug advertising, continuing medical education, and physician prescribing: a historical review and reform proposal. J Law Med Ethics 38:807-815

Salari K (2009) The dawning era of personalized medicine exposes a gap in medical education. PLoS Med 6:e1000138

Singh I, Rose N (2009) Biomarkers in psychiatry. Nature 460:202-207

SureGene (2010) SureGene, LLC. http://www.suregene.net/. Accessed 22 Feb 2011

Wade CH, Wilfond BS (2006) Ethical and clinical practice considerations for genetic counselors related to direct-to-consumer marketing of genetic tests. Am J Med Genet C Semin Med Genet 142:284-292

Wadman M (2008) Gene-testing firms face legal battle. Nature 453:1148 1149 